\title{
Development and Validation of a Method for Simultaneous Determination of Metformin Hydrochloride and Sitagliptin Phosphate in a Formulation by RP-HPLC
}

\author{
P. B. N. Prasad ${ }^{*}$, K. Satyanarayana ${ }^{2}$, G. Krishnamohan ${ }^{3}$ \\ ${ }^{1}$ Central Drugs Testing Laboratory, Hyderabad, India \\ ${ }^{2}$ NATCO Pharma R\&D, Hyderabad, India \\ ${ }^{3}$ Department of Pharmacy, JNTUH, Hyderabad, India \\ Email: pulijala bnprasad@yahoo.com
}

Received 1 June 2014; revised 19 July 2014; accepted 4 August 2014

Copyright @ 2014 by authors and Scientific Research Publishing Inc.

This work is licensed under the Creative Commons Attribution International License (CC BY).

http://creativecommons.org/licenses/by/4.0/

c) () Open Access

\begin{abstract}
Present study was aimed to develop and validate a reverse-phase high-performance liquid chromatography method for simultaneous determination of sitagliptin phosphate and metformin hydrochloride in a marketed formulation. The drug separation was performed on Hibar-240, Lichrosphere-100 C18 ODS $(250 \times 4.6 \mathrm{~mm}, 5 \mu \mathrm{m})$ column, at a flow rate of $1 \mathrm{~mL} / \mathrm{min}$. The mobile phase used was a mixture of methanol: potassium di-hydrogen phosphate buffer at a ratio of 70:30 v/v. The detection was carried out at a wavelength of $266 \mathrm{~nm}$. The retention times of sitagliptin phosphate and metformin hydrochloride were found as 6.1 and $4.9 \mathrm{~min}$ respectively. Linear calibration curves with good correlation coefficients were obtained over the concentration ranges of 10 - 50 $\mu \mathrm{g} / \mathrm{mL}$ for sitagliptin and $20-100 \mu \mathrm{g} / \mathrm{mL}$ for metformin. The limit of detection was 0.016 and 0.14 $\mu \mathrm{g} / \mathrm{mL}$ and the limit of quantification was 0.048 and $0.42 \mu \mathrm{g} / \mathrm{mL}$ for sitagliptin phosphate and metformin hydrochloride respectively. Validation of the method demonstrated system selectivity, specificity, linearity, accuracy and precision. The developed method was found useful in the simultaneous analysis of sitagliptin phosphate and metformin hydrochloride in formulation.
\end{abstract}

\section{Keywords}

Sitagliptin Phosphate, Metformin Hydrochloride, Reverse Phase High Performance Liquid Chromatography (RPHPLC), International Committee on Harmonization (ICH) Guidelines, Limit of Detection (LOD), Limit of Quantitation (LOQ), Linearity, Precision, Accuracy \& Reproducibility

${ }^{*}$ Corresponding author.

How to cite this paper: Prasad, P.B.N., Satyanarayana, K. and Krishnamohan, G. (2014) Development and Validation of a Method for Simultaneous Determination of Metformin Hydrochloride and Sitagliptin Phosphate in a Formulation by RP-HPLC. American Journal of Analytical Chemistry, 5, 737-742. http://dx.doi.org/10.4236/ajac.2014.511082 


\section{Introduction}

Dipeptidyl peptidase-4 (DPP-4) inhibitors are emerged as a new class of oral hypoglycemic agents in the treatment of diabetes. This class of agents is acted by the inhibition of the incretins inactivation, specifically glucagonlike peptide-1 (GLP-1) and gastric inhibitory polypeptide (GIP), thereby improving glycemic control. Sitagliptin phosphate is an orally active DPP-4 inhibitor and it is chemically 7-[(3R)-3-amino-1-oxo-4-(2,4,5-trifluorophenyl)butyl]-5,6,7,8-tetrahydro-[3-(trifluoromethyl)-1,2,4-triazolo[4,3-alpha]pyrazine phosphate (1:1) monohydrate. Sitagliptin also enhances glycemic control and shows a positive influence on the growth of $\beta$-cells in pancreatic islets [1]-[4]. Metformin (MET), N,N-dimethylimidodicarbonimidic diamide is a biguanide drug that stimulates glycolysis in peripheral tissues [5]. Metformin lowers hepatic glucose production via a still unknown mechanism [6]. Insufficient glycemic control with first line drugs results into combination therapy with either oral hypoglycemic agents or insulin to patient's treatment regimen [7].

Recently, the combination of sitaglipin and metformin has been recommended for use in the treatment of diabetes mellitus to improve glycemic control [8]. Already few methods were reported for the determination of sitagliptin in pharmaceutical formulations or biological samples by spectrophotometry and HPLC [5]. Analytical methods for determination of metformin include normal phase chromatography (silica and cyano), cation exchange chromatography, ion pair chromatography and reversed phase chromatography with UV or mass spectrometric detection [9].

The present work presents development and validation of a new and simple RP-HPLC method for simultaneous determination of metformin hydrochloride and sitagliptin phosphate in a formulation.

\section{Experimental}

\subsection{Materials and Reagents}

HPLC grade acetonitrile and methanol were purchased from Sigma Aldrich (Bangalore, India). Analytical grade solvents namely Butanol, Methanol, Chloroform, Diethyl amine, Potassium dihydrogen phosphate and Formic acid were purchased from Sigma Aldrich (Bangalore, India). Pharmaceutical grade sitagliptin was a gift sample from Merck Sharp \& Dohme (Cairo, Egypt). Metfromin was generous gift sample obtained from Aurobindo Pharmaceuticals Pvt Ltd. (Hyderabad, India). Janumet ${ }^{\circledR}$ tablets nominally containing $50 \mathrm{mg}$ of sitagliptin phosphate monohydrate and $500 \mathrm{mg}$ of metformin per tablet were all kindly supplied by Merck Sharp and Dohme Co. (Cairo, Egypt).

\subsection{Instrumentation and Chromatography}

The HPLC system consisted of a Shimadzu LC-20AD pumps, SPD-20A UV detector, SPD-M10A VP diode array detector. The method was developed on Hibar-240, Lichrosphere-100 C18 ODS ( $250 \times 4.6 \mathrm{~mm}, 5 \mu \mathrm{m})$ column. The data acquisition was performed by processing software "LC Solution" (Shimadzu Corp.).

The mobile phase was a mixture of methanol and potassium di-hydrogen phosphate buffer taken at a ratio of $70: 30 \mathrm{v} / \mathrm{v}$, delivered at a flow rate of $1 \mathrm{~mL} / \mathrm{min}$. The column was maintained at $30^{\circ} \mathrm{C}$ and the detection was carried out at a wavelength of $261 \mathrm{~nm}$ (PDA, UV). The injection volume was $20 \mu \mathrm{L}$.

\subsection{Preparation of the Standard Solutions}

\subsubsection{Stock and Working Standard Solutions}

The stock solution of sitagliptin $(5000 \mu \mathrm{g} / \mathrm{mL})$ and metformin $(50,000 \mu \mathrm{g} / \mathrm{mL})$ was prepared by taking $50 \mathrm{mg}$ and $500 \mathrm{mg}$ of sitagliptin and metformin respectively into a $10 \mathrm{~mL}$ volumetric flask. Standard drugs were dissolved in $3 \mathrm{~mL}$ methanols and sonicated for 5 minutes followed by made up to the volume with the addition of methanol. From the stock solutions, working solutions of sitagliptin and metformin were prepared in 1 - 1000 $\mu \mathrm{g} / \mathrm{mL}$ and $10-10,000 \mu \mathrm{g} / \mathrm{mL}$ concentration range, respectively.

\subsubsection{Sample Preparation}

Ten tablets were weighed and the coats were removed. An accurately weighed amount of finely powdered janumet tablets equivalent to $500 \mathrm{mg}$ of metformin and $50 \mathrm{mg}$ of sitagliptin were taken into a volumetric flask and 3 $\mathrm{mL}$ of methanol was added. Followed by sonication for 25 minutes and then made up to $10 \mathrm{~mL}$ with methanol. 
The solutions were filtered and prepared dilutions to $1 \mu \mathrm{g} / \mathrm{mL}$ of sitagliptin and $10 \mu \mathrm{g} / \mathrm{mL}$ of metformin.

\section{Results and Discussion}

\subsection{Method Validation}

The method validation was performed in accordance with ICH guidelines [10]. The parameters assessed were linearity, accuracy, limit of detection (LOD), limit of quantification (LOQ), precision, reproducibility and robustness.

\subsubsection{Selectivity and Specificity}

A representative chromatogram of the standard drugs is shown in Figure 1. No additional peaks were observed. Figure 2 shows the chromatograms of standard drug contain $98.15 \%$ and $99.4 \%$ of sitagliptin and metformin respectively. The retention time of metformin and sitagliptin were found at 4.9 and 6.1 min respectively. Assay (\%) $98 \%-102 \%$ this is in accordance with ICH guidelines. Hence the developed method can be routinely employed for the simultaneous estimation of sitagliptin and metformin in the marketed formulations. Assay values of sitagliptin and metformin were presented in Table 1.

\subsubsection{Linearity}

Linear calibration curves with correlation coefficients greater than 0.9999 were obtained over a concentration range of $10-50 \mu \mathrm{g} / \mathrm{mL}$ for sitagliptin and $20-100 \mu \mathrm{g} / \mathrm{mL}$ for metformin. The typical equation of the calibration curves of the both drugs were obtained with $r$ value 0.998 . The results shown that within the concentration range indicated there was an excellent correlation between peak area ratio and each concentration of the sitagliptin and metformin.

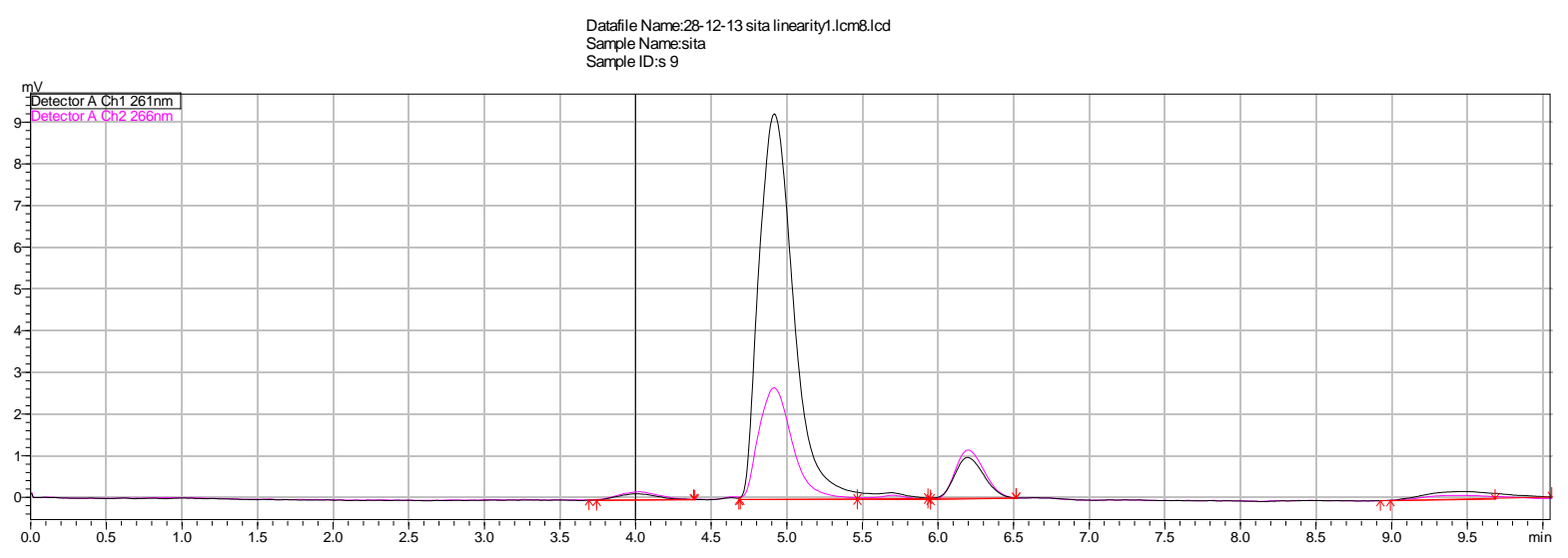

Figure 1. Chromatogram of standard.

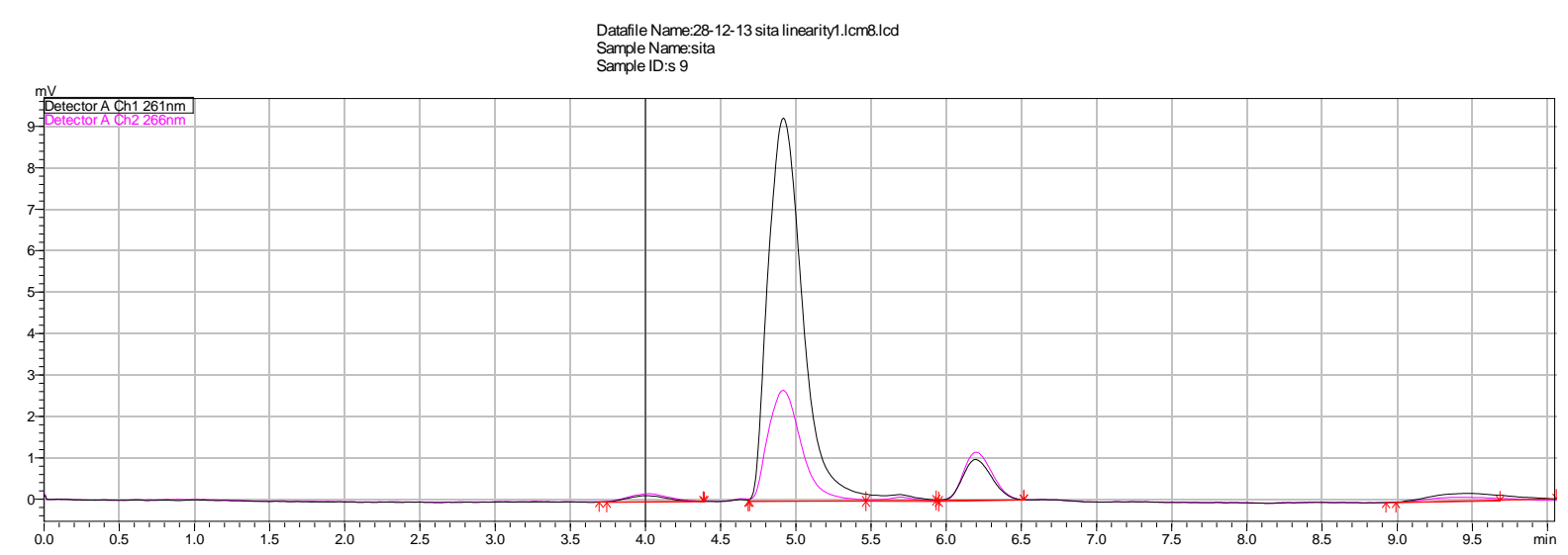

Figure 2. Chromatogram of sample. 


\subsubsection{Limit of Detection and Limit of Quantification}

The limit of detection (LOD) and limit of quantification (LOQ) were calculated for sitagliptin and metformin according to ICH guidelines by taking standard deviation and slope from the calibration curve. LOD and LOQ were calculated by using below formulae

$$
\text { LOD }-3.3 \times \text { SD/slope; LOQ }-10 \times \text { SD/slope }
$$

LOD and LOQ values were presented in Table 2.

\subsubsection{Precision}

Precision of the analytical method was determined by replicating the process in triplicates at 3 different concentrations of sitagliptin and metformin (combination) and chromatograms were recorded. Precision was calculated as a percentage relative standard deviation. The relative standard deviation should be less than 2 according to ICH guidelines. The \% relative standard deveiation of sitagliptin $(2,4,6 \mu \mathrm{g} / \mathrm{mL})$ and metfromin $(20,40,60$ $\mu \mathrm{g} / \mathrm{mL}$ ) was found less than $2 \%$. Precision data of sitaglitin and metfromin were given in Table 3 and Table 4 respectively.

\subsubsection{Accuracy and Recovery Studies}

To the pre analyzed samples known amount of standard solutions in different concentration levels (50\%, 100\% and $150 \%$ ) were added. For these solutions chromatograms were developed to record accuracy and recovery. The recoveries of sitagliptin and metformin were determined at 3 concentration levels (low, medium, high). Accuracy of the method was treated as percent recovery. Recoveries of sitagliptin (Table 5) and metformin (Table 6) were in between $98 \%-102 \%$. This is in accordance with ICH guidelines. Therefore method was found to be accurate.

Table 1. Assay of sitagliptin and metformin.

\begin{tabular}{ccc}
\hline Parameters & Sitagliptin & Metformin \\
\hline Standard peak area & 15,067 & 148,722 \\
Test peak area & 14,985 & 146,128 \\
Average weight & $704 \mathrm{mg}$ & $704 \mathrm{mg}$ \\
Label claim & $50 \mathrm{mg}$ & $500 \mathrm{mg}$ \\
\% Purity of standard & 99.8 & 99.9 \\
Amt obtained & $49.25 \mathrm{mg}$ & 490.0 \\
\% Assay & $98.15 \%$ & $99.4 \%$ \\
\hline
\end{tabular}

Table 2. LOD \& LOQ.

\begin{tabular}{ccc}
\hline & Sitagliptin & Metformin \\
\hline LOD & $0.016 \mu \mathrm{g} / \mathrm{mL}$ & $0.14 \mu \mathrm{g} / \mathrm{mL}$ \\
LOQ & $0.048 \mu \mathrm{g} / \mathrm{mL}$ & $0.42 \mu \mathrm{g} / \mathrm{mL}$ \\
\hline
\end{tabular}

Table 3. Precision data of sitagliptin.

\begin{tabular}{cccc}
\hline Concentration $(\boldsymbol{\mu g} / \mathbf{m L})$ & Mean & Standard deviation & Relative standard deviation (\%) \\
\hline 2 & 5748 & 16 & 0.27 \\
4 & 13,052 & 389.68 & 1.98 \\
6 & 24,301 & 210.53 & 0.86 \\
\hline
\end{tabular}


Table 4. Precision data of metformin.

\begin{tabular}{cccc}
\hline Concentration $(\boldsymbol{\mu g} / \mathbf{m L})$ & Mean & Standard deviation & Relative standard deviation (\%) \\
\hline 20 & 77,196 & 172.17 & 0.22 \\
40 & 143527.6 & 964.88 & 0.67 \\
60 & 238452.6 & 1146.78 & 0.48 \\
\hline
\end{tabular}

Table 5. Recovery of sitagliptin.

\begin{tabular}{ccccc}
\hline Sample \% level & Amount added $(\boldsymbol{\mu g} / \mathbf{m L})$ & Amount found $(\boldsymbol{\mu g} / \mathbf{m L})$ & $\%$ Recovery & Mean recovery \\
\hline $50 \%$ & 6 & 5.95 & 99.1 & 98.2 \\
$50 \%$ & 6 & 5.86 & 97.6 & 99.9 \\
$50 \%$ & 6 & 5.89 & 98.1 & \\
\hline $100 \%$ & 8 & 7.98 & 99.7 & 98.75 \\
$100 \%$ & 8 & 7.90 & 101.25 & 99.6 \\
$100 \%$ & 8 & 8.1 & 101 & 99 \\
10 & 10 & 10.1 & 98.9 \\
\hline
\end{tabular}

Table 6. Recovery of metformin.

\begin{tabular}{ccccc}
\hline Sample \% level & Amount added $(\boldsymbol{\mu g} / \mathbf{m L})$ & Amount found $(\boldsymbol{\mu g} / \mathbf{m L})$ & \% Recovery & 98.8 \\
\hline $50 \%$ & 60 & 59.3 & 99.6 & 100.1 \\
$50 \%$ & 60 & 59.8 & 99.25 \\
$50 \%$ & 60 & 60.1 & 98.8 \\
\hline $100 \%$ & 80 & 79.4 & 100.1 \\
\hline $100 \%$ & 80 & 79.1 & 99.38 \\
$100 \%$ & 80 & 80.1 & 99.8 \\
$150 \%$ & 100 & 99.8 & 100.3 \\
\hline
\end{tabular}

\section{Conclusion}

A simple, selective and sensitive reverse phase HPLC analysis method was developed for the simultaneous estimation of sitagliptin and metfromin in marketed formulation. The method was found economical and simple with involvement of few steps. The assay has been validated as per the ICH guideline and the results have shown that the method is sensitive, accurate and reproducible. Therefore, the developed method is found suitable for the simultaneous determination of sitagliptin and metformin in formulations.

\section{Acknowledgements}

The authors are thankful to Merck Sharp \& Dohme (Cairo, Egypt) for the gift samples of sitagliptin. Metfromin was generous gift sample obtained from Aurobindo Pharmaceuticals Pvt Ltd. (Hyderabad, India). 


\section{References}

[1] Rao, R.N., Maurya, P.K. and Khalid, S. (2011) Development of a Molecularly Imprinted Polymer for Selective Extraction Followed by Liquid Chromatographic Determination of Sitagliptin in Rat Plasmaand Urine. Talanta, 85, 950-957. http://dx.doi.org/10.1016/j.talanta.2011.05.002

[2] Sengupta, P., Bhaumik, U., Ghosh, A., Sarkar, A.K., Chatterjee, B., Bose, A. and Pal, T.K. (2009) LC-MS-MS Development and Validation for Simultaneous Quantitation of Metformin, Glimepiride and Pioglitazone in Human Plasma and Its Application to a Bioequivalence Study. Chromatographia, 69, 1243.

http://dx.doi.org/10.1365/s10337-009-1056-5

[3] Herman, G.A., Bergman, A., Stevens, C., Kotey, P., Yi, B., Zhao, P., et al. (2006) Effect of Single Oral Doses of Sitagliptin, a Dipeptidyl Peptidase-4 Inhibitor, on Incretin and Plasma Glucose Levels after an Oral Glucose Tolerance Test in Patients with Type 2 Diabetes. The Journal of Clinical Endocrinology and Metabolism, 91, 4612-4619. http://dx.doi.org/10.1210/jc.2006-1009

[4] Herman, G.A., Stevens, C., Van Dyck, K., Bergman, A., Yi, B., De Smet, M., et al. (2005) Pharmacokinetics and Pharmacodynamics of Sitagliptin, an Inhibitor of Dipeptidyl Peptidase IV, in Healthy Subjects: Results from Two Randomized, Double-Blind, Placebo-Controlled Studies with Single Oral Doses. Clinical Pharmacology and Therapeutics, 78, 675-688. http://dx.doi.org/10.1016/j.clpt.2005.09.002

[5] El-Bagary, R.I., Elkady, E.F. and Ayoub, B.M. (2011) Liquid Chromatographic Determination of Sitagliptin either Alone or in Ternary Mixture with Metformin and Sitagliptin Degradation Product. Talanta, 85, 673-680. http://dx.doi.org/10.1016/j.talanta.2011.04.051

[6] Fonseca, V., Staels, B., Morgan II, J.D., Shentu, Y., Golm, G.T., Johnson-Levonas, A.O., Kaufman, K.D., Goldstein, B.J. and Steinberg, H. (2013) Efficacy and Safety of Sitagliptin Added to Ongoing Metformin and Pioglitazone Combination Therapy in a Randomized, Placebo-Controlled, 26-Week Trial in Patients with Type 2 Diabetes. Journal of Diabetes and Its Complications, 27, 177-183. http://dx.doi.org/10.1016/j.jdiacomp.2012.09.007

[7] American Diabetes Association (2012) Standards of Medical Care in Diabetes_-2012. Diabetes Care, 35, S11-S63. http://dx.doi.org/10.2337/dc12-s011

[8] Salsali, A. and Pratley, R. (2007) Does Addition of Sitagliptin to Metformin Monotherapy Improve Glycemic Control in Patients with Type 2 Diabetes Mellitus. Nature Reviews Endocrinology, 3, 450.

[9] Liu, A. and Coleman, S.P. (2009) Determination of Metformin in Human Plasma Using Hydrophilic Interaction Liquid Chromatography-Tandem Mass Spectrometry. Journal of Chromatography B, 877, 3695-3700. http://dx.doi.org/10.1016/j.jchromb.2009.09.020

[10] The ICH Steering Committee (1996) Harmonized Triplicate Guideline on Validation of Analytical Procedures: Methodology, Recommended for Adoption at Step 4 of the ICH Process. International Conference on Harmonization (ICH) of Technical Requirements for Registration of Pharmaceutical for Human Use, November 1996, IFPMA, Switzerland. 